\title{
Genome-wide studies of telomere biology in budding yeast
}

\author{
Yaniv Harari and Martin Kupiec* \\ Department of Molecular Microbiology and Biotechnology, Tel Aviv University, Ramat Aviv 69978, Israel. \\ * Corresponding Author: Martin Kupiec, Tel Aviv University; Ramat Aviv 69978, Israel; Tel: +972-3-640-9031; Fax: +972-3-640-9407; \\ E-mail: martin@post.tau.ac.il
}

\begin{abstract}
Telomeres are specialized DNA-protein structures at the ends of eukaryotic chromosomes. Telomeres are essential for chromosomal stability and integrity, as they prevent chromosome ends from being recognized as double strand breaks. In rapidly proliferating cells, telomeric DNA is synthesized by the enzyme telomerase, which copies a short template sequence within its own RNA moiety, thus helping to solve the "end-replication problem", in which information is lost at the ends of chromosomes with each DNA replication cycle. The basic mechanisms of telomere length, structure and function maintenance are conserved among eukaryotes. Studies in the yeast Saccharomyces cerevisiae have been instrumental in deciphering the basic aspects of telomere biology. In the last decade, technical advances, such as the availability of mutant collections, have allowed carrying out systematic genome-wide screens for mutants affecting various aspects of telomere biology. In this review we summarize these efforts, and the insights that this Systems Biology approach has produced so far.
\end{abstract}

doi: $10.15698 /$ mic2014.01.132 Received originally: 20.01 .2014 in revised form: 14.02.2014,

Accepted 16.02.2014

Published 01.03.2014.

Keywords: yeast, telomeres, genome stability, cancer, aging, systems biology.

\section{INTRODUCTION}

The ends of the eukaryotic chromosomes are protected by special nucleoprotein structures called telomeres. Telomeres play pivotal roles in maintaining the stability of the genome: they serve to distinguish between the natural chromosomal ends, which should not be repaired, and double stranded DNA breaks (DSBs), which need to be repaired urgently to prevent loss of genomic information. DSBs occur often, due to external insults, or to the normal metabolism of the cell [1]. Telomeres protect the chromosomal ends by virtue of the special chromatin configuration conferred by telomeric proteins, as well as by particular three-dimensional folding of the DNA $[2,3]$. In addition, telomeres provide a solution to the "end-replication problem": due to the need for primers, the regular DNA polymerases are unable to fully replicate the chromosomal ends $[4,5]$; this problem is exacerbated by resection of the ends by nucleases, which leads to loss of information from the chromosomal ends in each cell division. Eventually most somatic cells senesce and stop dividing [6-8].

Unicellular organisms and embryonic mammalian cells, which are highly proliferative, solve the end-replication problem by expressing telomerase $[9,10]$, a specialized reverse transcriptase able to extend the telomeres by copying telomeric sequences from an internal RNA template.
Telomerase is not expressed in most somatic cells; strikingly, it suffices to express a functional and active telomerase to overcome cellular senescence in these cells [11]. Cancer cells are also highly proliferative, and therefore require functional telomeres: in about $80 \%$ of tumors, the telomerase gene is expressed [12]; in the rest, an alternative mechanism, based on homologous recombination, allows telomere length extension (alternative lengthening of telomeres or ALT; reviewed in [13]). Moreover, replenishing telomeres is one of the few essential steps that a normal mammalian fibroblast must take in order to become cancerous [14]. Mutations that affect telomere function result in human diseases, such as Idiopathic Pulmonary Fibrosis, Dyskeratosis Congenita, and others [15-17]. Thus, our understanding of the biology of telomeres has significant medical implications, in particular for the fields of aging and cancer.

Although differences exist in the composition and organization of telomeres in yeast and mammals, many basic rules are universal. In 2009 Elizabeth Blackburn, Carol Greider and Jack Szostak received the Nobel Prize in Medicine for their work on telomeres and telomerase. Much of this work was carried out in model organisms, including the yeast Saccharomyces cerevisiae. Other yeasts, particularly $K$. lactis and S. pombe, have also contributed extensively to 
our understanding of telomere biology. In this review we will concentrate particularly on S. cerevisiae.

\section{COMPOSITION OF YEAST TELOMERES}

The basic structure of the yeast telomere is depicted in Figure 1. The RNA template of telomerase (encoded by the TLC1 gene) bears the template sequence CACACACCCACACCAC [18]. However, the telomeric sequence in $S$. cerevisiae is not regular, and can be described as $T\left(G_{1-3}\right)[19,20]$. Thus, only very short stretches are copied in each round of telomerase activity from the RNA template [21]. This contrasts with the sequence regularity observed in other organisms, such as K. lactis [22].

A number of proteins bind yeast telomeres:

Rap1: Rap1, an essential DNA binding protein, recognizes and binds to the yeast telomeric DNA repeats, and serves to determine telomere length by a "counting" mechanism that monitors Rap1 concentration (Figure 1B) [23-25]. Rap1 also contributes to telomere capping and prevents repair of the telomeres as regular double-stranded breaks, as well as playing roles in localizing telomeres to the nuclear periphery [26-28]. In addition to its telomeric role, Rap1 also works as a general cellular transcriptional activator and repressor that binds to upstream promoter regions at a large number of genes and interacts with various regulatory proteins $[29,30]$.

Rif1 and Rif2: Two proteins, Rif1 and Rif2, bind the Cterminal region of Rap1 (Figure 1B) [31, 32]. Cells mutated for RIF1 or RIF2 exhibit long telomeres, indicating that the function of these proteins is to negatively regulate the elongation of telomeres [31, 32]. Rif1 and Rif2 binding confers to Rap1-bound telomeric DNA a higher order structure by interconnecting different Rap1 units. The functional importance of this structure, and its role in telomere biology are still unclear [33]. Despite the coordinated binding, Rif1 and Rif2 seem to work separately of each other. As
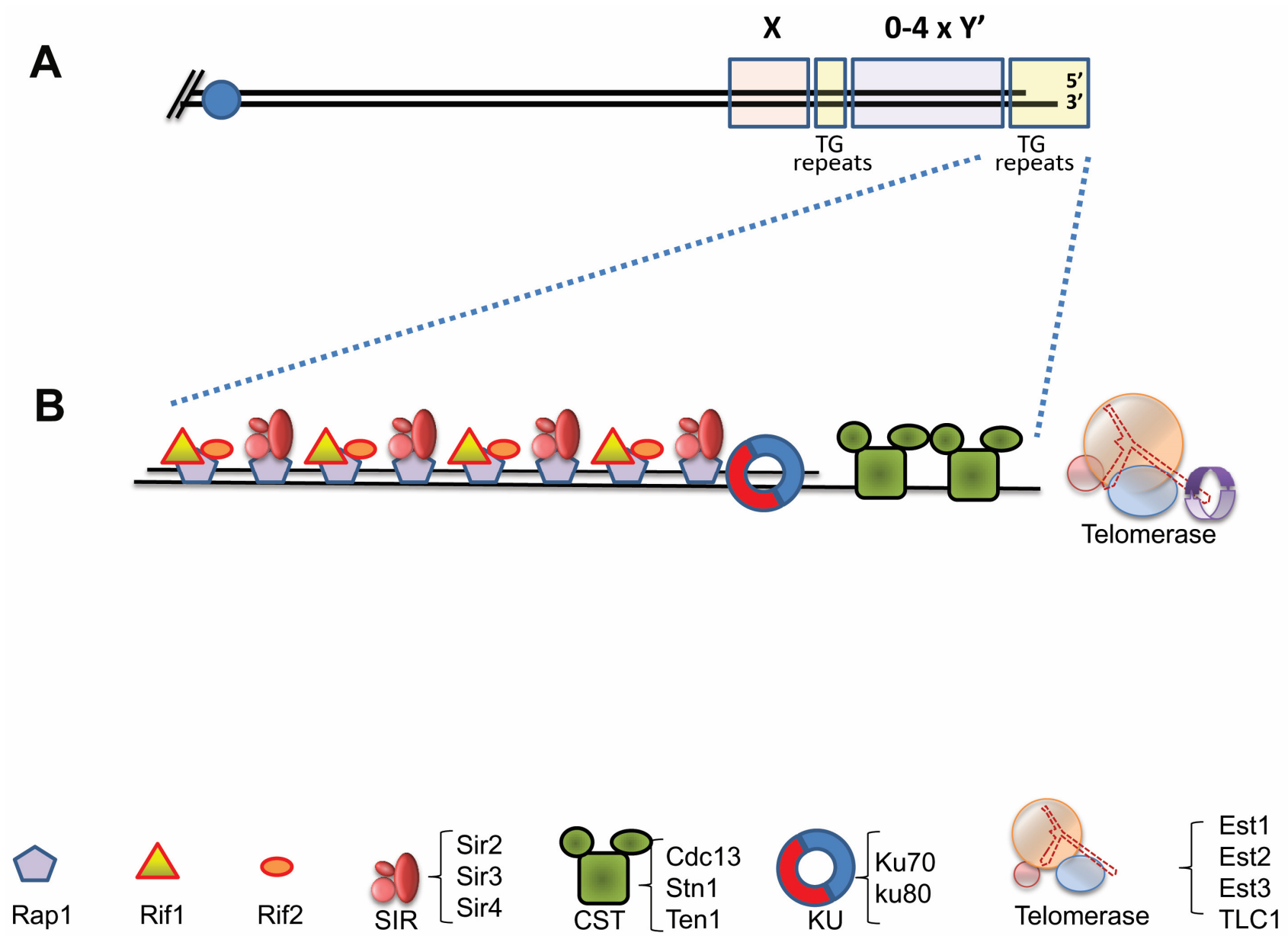

FIGURE 1: Structure of the yeast telomere. (A) Schematic representation of a yeast telomere. All yeast chromosomes carry subtelomeric repeats called $X$ elements, and between 0 and 4 copies of another sub-telomeric element, the $Y^{\prime}$ sequences. Telomeric repeats are composed of variations of the T(G1-3) formula. The TG-rich strand (with its 3' OH) is longer than the complementary strand (TG overhangs). (B) Schematic representation of the telomeric chromatin, with representative proteins. Rap1 binds the telomeric repeats, and Rif1, Rif2 and the SIR proteins bind to Rap1. The Ku heterodimer binds to telomeric dsDNA and the CST complex binds the terminal ssDNA end. Telomerase is recruited to telomeres present in an "extensible" configuration by interactions with the CST. 
explained above, rif1 and rif2 mutants show elongated telomeres. The double mutant, however, exhibits much longer and unregulated telomeres, indicating that the two proteins participate in alternative regulatory mechanisms $[32,34]$.

Yku70 and Yku80: $\mathrm{Ku}$ is a conserved complex composed of two proteins of $\sim 70$ and $\sim 85 \mathrm{kDa}$ (Yku70 and Yku80 in yeast). It plays central roles in DSB repair by nonhomologous end joining (NHEJ), a mechanism in which the broken ends are ligated together irrespectively of their sequence [35]. Since NHEJ must be avoided at telomeres (to prevent fusions between chromatids or chromosomes), it is surprising that $\mathrm{Ku}$ is also a natural component of telomeres. However, Ku plays an essential role in telomere maintenance (Figure 1B, reviewed in [1]). The Ku complex is associated with telomerase RNA (TLC1) and participates in the import of TLC1 to the nucleus [36], and possibly in the recruitment of telomerase [37-39]. Moreover, the Ku heterodimer helps in anchoring the telomeres to the perinuclear space [28] by a still mysterious mechanism that involves the small protein modifier SUMO [40]. Finally, Ku presence seems to prevent exonucleolytic activity at broken chromosomes and at telomeres [41-43]. Thus, Ku affects almost all aspects of telomere biology, although it is not completely essential for life. Interestingly, specific mutations have been found, which separate the roles that $\mathrm{Ku}$ plays in NHEJ and in telomere biology [44, 45].

The CST complex: Another conserved complex is composed of the Cdc13, Stn1 and Ten1 proteins. This complex structurally resembles Replication Protein A (RPA), which binds ssDNA during cellular DNA replication and DNA repair (reviewed in [46]). The CST binds single-stranded telomeric repeats through OB folds, a common motif in SSDNA and RNA binding proteins (Figure 1B) [47]. It has been proposed that the CST out-competes and replaces RPA at telomeres; however, RPA can also be detected at telomeres, and is probably functional during DNA replication [48-50]. Thus, a division of work between the CST and RPA must exist, which is probably intricately linked to the mechanism of replication of telomeres. Stn1 and Ten1, the two proteins associated with $\mathrm{Cdc} 13$, were isolated as genetic and physical interactors of Cdc13 [51, 52]. The interactions between these proteins are complex: Stn 1 and Ten1 appear to regulate the activity of Cdc13 [46]; on the other hand, mutations in STN1 [52] or overexpression of both Stn 1 and Ten 1 can suppress the lethality of the temperature-sensitive $c d c 13-1$ mutants $[53,54]$. These results indicate the existence of activities of Stn1 and Ten 1 that are carried out independently of Cdc13.

The SIR complex: Due to the heterochromatic nature of telomeres, in many organisms genes located close to telomeres undergo silencing (also called telomere position effect or TPE). This silencing depends on the Silent Information Regulator (SIR) complex, which consists of three proteins, Sir2, Sir3 and Sir4 (Figure 1B) [55]. The complex is recruited to telomeres by interactions with Rap1 and plays also a role in tethering telomeres to the nuclear envelope.

Telomerase: Yeast telomerase consists of three proteins, Est1-3 and an RNA molecule encoded by the TLC1 gene; Est2 contains the catalytic activity [56]. The name "Est" comes from genetic screens that originally identified "ever shorter telomere" mutants, defective in telomerase activity $[8,57]$. The exact role of Est 1 and Est 3 in telomerase function is still not completely understood. In strains carrying a fusion between $\mathrm{Cdc13}$ and the Est2 catalytic subunit, the essential Est1 subunit becomes dispensable, demonstrating that telomerase is recruited by the Cdc13-Est1 interaction, and this recruitment seems to be the only essential function of Est1 [58, 59]. However, recruitment of Est2 cannot be the sole function of Est1 since mutant Est1 proteins, that retain association with the telomerase enzyme, still affect telomere length [60]. In addition, Est1 also favors telomerase-mediated DNA extension in vitro through a direct contact with Est2 [61].

\section{ROLES OF TELOMERES IN END PROTECTION AND GENOME REPLICATION}

One of the main functions of the telomere is to prevent the cell from repairing its natural chromosomal ends as if they were chromosomal double-stranded breaks (DSBs). This function, called telomere capping, is extremely important: DSBs are among the most serious types of DNA damage a cell can undergo, and efficient response mechanisms have evolved to cope with the presence of even a single DSB. However, attempts by the cells to repair natural telomeres as if they were broken chromosomes will lead to chromatid or chromosomal fusions, starting a cycle of fusions and breakages that will increase genome instability, and thus cell death and/or cancer development $[1,62]$.

If telomeres become uncapped, the cells recognize the presence of broken DNA ends, and react by eliciting the DNA Damage Response (DDR), which in yeast is controlled by the Tel1 and Mec1 protein kinases (orthologs of mammalian ATM and ATR). This response includes cell cycle arrest, and attempts to repair the damage (reviewed in [1]). Indeed, when telomeres become uncapped, the cells attempt repair of the exposed DNA ends; a robust resection of the telomeric DNA by nucleases can be observed, as well as telomere-telomere fusions [26, 63-65]. The genetic control of resection differs from the one observed at nontelomeric DSBs: the MRX complex, which usually participates in the initiation of resection, inhibits resection at telomeres, and mutations in the MRX genes exhibit increased SsDNA levels (Foster et al., 2006). An elegant labeling experiment demonstrated that MRX binds specifically to leading-strand telomeres, where it could generate SSDNA for the CST to bind [66].

Telomere uncapping may result as a consequence of inactivation of CST components [63], or of the Ku heteroduplex $[42,67]$. Similarly to the CST and Ku complexes, the Rap1-Rif1-Rif2 complex plays a role in telomere capping. 
However, Rap1 inactivation leads to cell cycle arrest at G1 instead of the Mec1-dependent $\mathrm{G} 2$ arrest [68].

As explained above, telomerase plays an important role in solving the "end-replication problem" $[4,5]$. Telomerase is recruited to short chromosomes, which are said to be in an "extensible" configuration [69] (Figure 2). The molecular determinant of this state is still unclear, and may represent a particular protein configuration, a particular state of the DNA/chromatin, or be related to the tethering of telomeres to the nuclear envelope. Telomerase activity must be somehow coordinated with the replication of the rest of the genome. Replication origins located close to telomeres replicate very late in the S-phase of the cell cycle [70]; curiously, this phenomenon is independent of the replication origin sequence: any origin located near telomeres is fired late, by a still enigmatic mechanism [71].

The coordination between telomere and genomic replication is complex, and not completely understood. Te- lomerase is recruited to the shortest telomeres by a mechanism that is regulated by Tel1 (ATM) [72]. The level of Cdc13, Est1 and Est3 increases at these telomeres by the end of S-phase, consistent with a model in which telomerase is recruited by interactions between Est1 and the CST [59]. Surprisingly, the catalytic subunit, Est2, is present at the telomerase throughout the cell cycle; the significance of this fact is still not understood. The Est1 telomeric subunit becomes dispensable in strains carrying a fusion between Est2 and Cdc13, suggesting that its main function is to recruit telomerase [73]. The recruitment of Est3 to telomerase was shown to be Est1-dependent [58]. However, expression of Est1 in G1, which results in Est1 and Est3 recruitment to the Est2-TLC1 complex already present at telomeres, does not allow telomerase activation, indicating that additional conditions must be met for telomerase activation [74]. These could be CDK1-related (e.g., phosphorylation of one of the proteins by the activated CDK1 may
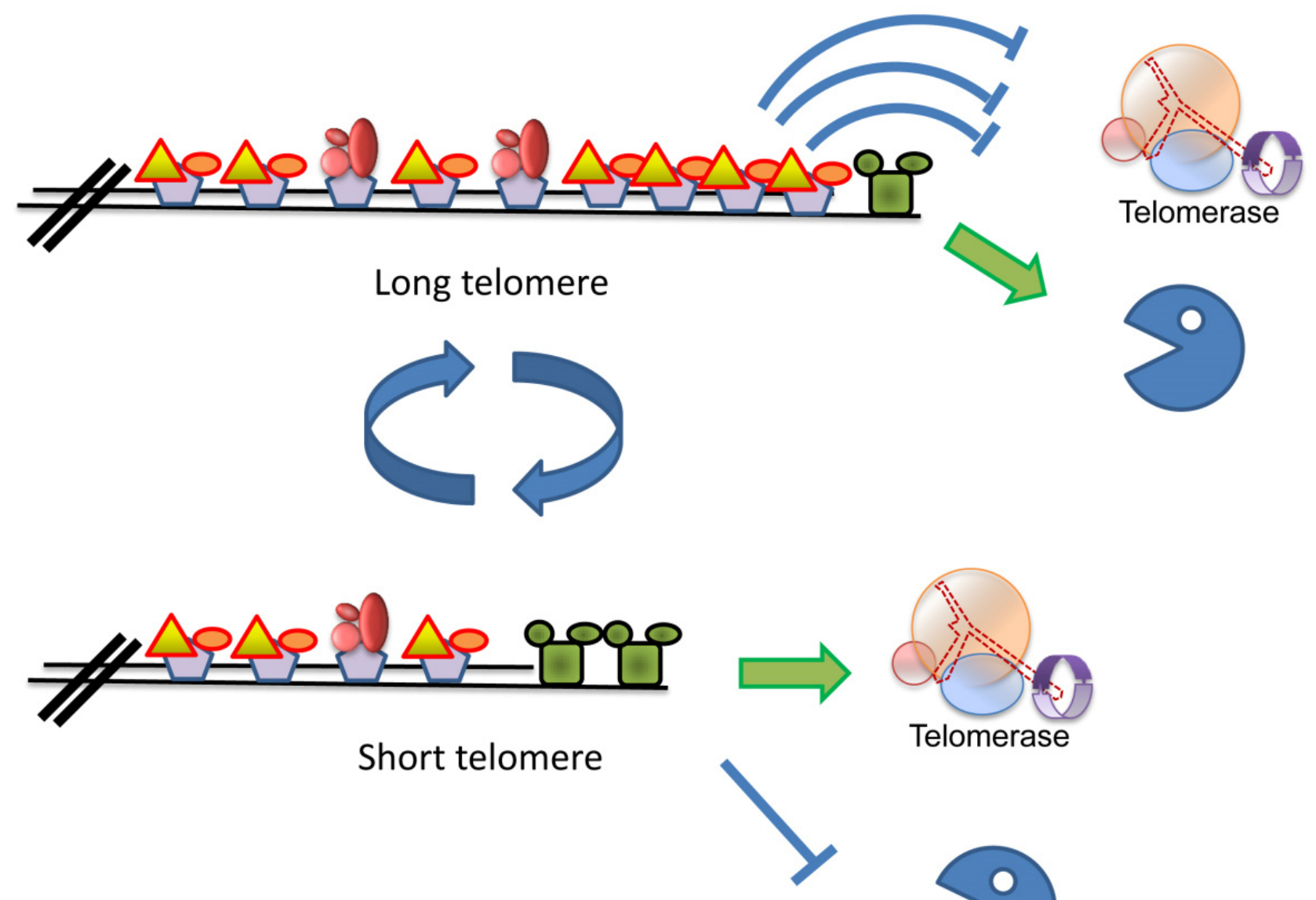

Telomerase

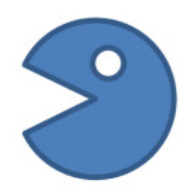

FIGURE 2: Schematic model of the mechanism(s) that keep telomere length homeostasis. Long telomeres carry many copies of the Rap1 protein, and its associated Rif1 and Rif2 proteins, which prevent recruitment of telomerase. Telomeres in this state are said to be in a "nonextendable" configuration [69]. Telomeres shorten as a consequence of the "end replication problem" or by the action of exonucleases (Pacman). It is still unclear what circumstances allow recruitment of nucleases. Short telomeres carry a low number of Rap1/Rif units, and the CST is able to recruit telomerase, thus elongating the telomere. It is assumed that the presence of an active telomerase prevents recruitment of shortening nucleases. 
be a pre-requisite), or the telomeric DNA may need to be in a particular molecular configuration for telomerase to act [69]. Interestingly, the Rif1 and Rif2 proteins and the Ku heteroduplex may also restrict $\mathrm{G} 1$ activation $[42,75,76]$.

\section{THE SYSTEMS BIOLOGY REVOLUTION}

In the last fifteen years, the efforts to get more systematic and complete information about the interactions between molecules resulted in the development of methodologies, such as the DNA microarray, which provide data about the status of the whole genome. This technical achievement lead to a change in attitude, which allowed turning the traditional reductionist approach of Molecular Biology upside-down, to attempt a whole-encompassing view of the cell. One could thus describe genetic or protein interactions in the same way an astronomer would describe relationships between stars in the sky. By analyzing large amounts of data one could discern the existence of order in the distribution of the bodies analyzed (e.g., galaxies in the sky or protein complexes in a cell), and attempt to decipher the rules behind their behavior. In addition, there are "emerging properties", which cannot be seen by looking at each gene/protein separately and require a "bird's eye view" to be discerned (as one can see a pattern in the distribution of highways in a map, that are hard to see while traveling a highway by car). A flurry of genome-wide methodologies was launched, in which a systematic approach was taken to try to map all the genes (genomics), RNA molecules (transcriptomics), proteins (proteomics), and metabolites (metabolomics) in a given organism. This "omics" revolution required dealing with increasing amounts of data, and new algorithms and computational approaches had to be developed. The easiness with which yeast cells can be grown and manipulated, combined with the already significant knowledge of yeast life-style, genes and proteins, made yeast (mainly Saccharomyces cerevisiae) a natural choice of organism in which to ask genome-wide questions. Technically, the new discipline of Systems Biology was driven by the sophisticated genetics of yeast, which allowed the construction of mutant collections, fusion protein collections, and many other tools. These, in turn, quickly became the basis for additional new genome-wide technologies [77]. The Systems Biology revolution is still ongoing, and a communal effort is being made to map, for example, all the genetic and physical interactions in the yeast cells. Interestingly, as time passes, the field as a whole is shifting from general questions about genome architecture and function, to more focused questions related to particular aspects of Biology, which are analyzed with a mixture of Systems and Molecular Biology. Here we summarize the efforts directed at studying the biology of telomeres at a system-level.

\section{GENOME-WIDE STUDIES OF TELOMERE BIOLOGY}

Telomere Biology is greatly benefitting from the new allencompassing approach, which greatly enlarged our knowledge about the genes involved in telomere biology and their regulation. The yeast genome has close to 6000 recognized genes. A collection of 4700 mutants was constructed by systematically deleting each individual nonessential gene in yeast (non-essential yeast mutant collection, [78]). This collection was later complemented by two additional mutants libraries encompassing all the essential genes (yeast has 1300 essential genes): either hypomorphic [79] or temperature-sensitive alleles [80] of each of the essential genes were created. In addition to allowing systematic crosses of all possible yeast mutants with a particular mutation/gene construct/reporter [81], these mutant collections allow researchers to carry out systematic mutant screens even if the phenotype of interest is not selectable. Once a biochemical assay (or a microscopic phenotype) is available, it can be applied in a systematic fashion to each member of the deletion collections, searching systematically for mutant strains defective for the particular assay. Even complex assays that take hours to carry out, or microscopic phenotypes that require complex and slow measurements can be performed in the whole mutant collections in batches, so that the whole collection can be screened in a matter of months.

Three publications reported the systematic screening of the mutant collections, looking for those mutants that affect telomere length (telomere length maintenance or t $/ m$ mutants). DNA was extracted from each individual yeast strain and telomere length was measured by Southern blot, using as probes telomeric repeats that hybridize to the terminal restriction fragment [82-84]. Together, these papers identified $\sim 400$ genes affecting telomere length (either shorter or longer than the wild type). To understand the strength of this approach, it suffices to mention that only 30 or so genes were known to affect telomere length at the time the screens were carried out [82]. This list of genes underscores the central role played by telomere biology in the yeast life cycle, as $~ 7 \%$ of the genome affects telomere length. Moreover, it also demonstrates the complexity of the challenge: telomere length is determined by mechanisms that elongate (telomerase) or shorten (nucleases) telomeres (each of which may be positively and negatively regulated). Mutation in any of the TLM genes changes the final telomere size; this means that each of the 400 genes participates in determining the equilibrium between the two types of activity. It is remarkable to observe that in each genetic background (e.g., S288c or W303) wild type cells exhibit always telomeres of the same size; thus, in the tug-of-war between elongating and shortening mechanisms, the equilibrium is always attained at the same telomere length. Thus, a very strong homeostatic mechanism is at play to ensure the exact telomere size for each cell (Figure 2). The genes uncovered in these screens, as expected, include those affecting DNA and chromatin metabolism, but almost all functions in the cell are also represented, including RNA and protein synthesis, traffic and modification, metabolic pathways, mitochondrial functions, etc. The challenge ahead, of course, is to determine how all these genes impinge on the telomere length determination.

Up to now we have extoled the advantages of the genome-wide approach. One should, however, also take into 
consideration the fact that, by dealing with thousands of genes, there will always be inevitable errors. Despite claiming "completeness", the mutant libraries are not always complete, as some mutants either fail to grow, accumulate suppressors, or exhibit aneuploidy and heterogeneous behavior. Moreover, one can also expect a number of handling errors. Thus, it is always advisable to confirm the identity of the mutant knockout by PCR, and to complement the phenotype of the mutant by introducing the wild type gene. Interestingly, attempts to carry out this type of validation uncovered an interesting phenomenon: in about $10 \%$ of the yeast deletion mutants, the phenotype observed is due to the effect that the deletion has had on the gene's neighbor, rather than to the lack of function of the deleted gene. One can complement the phenotype of a strain deleted for the $A$ gene with a plasmid carrying $B$, its neighboring gene, but not by a plasmid carrying the $A$ gene itself [85].

One should thus regard results obtained in a genomewide approach as candidates for validation, rather than as final results. The need to handle hundreds, and sometimes thousands of strains in parallel, does not always allow the detection of subtle differences, and may sometimes lead to contradictory results that can be resolved only by careful control experiments (e.g., [86] and [87]).

The availability of a near-complete list of TLM genes opens the door for new modes of exploration of telomere biology. A simple approach is to analyze, using Molecular Biology approaches, the mechanisms affecting telomere length in a certain subset of $t / m$ mutants. For example, Rog et al. took this approach to explore the role of vacuolar protein sorting (VPS) proteins, in charge of vacuolar traffic in the cell, in telomere length maintenance. The list of TLM genes is highly enriched for those encoding VPS proteins. The authors identified the pathway as being dependent on telomerase and $\mathrm{Ku}$, but independent of Tel1 and Rif2 [88].

As mentioned above, large amounts of information are being gathered about different aspects of yeast biology. Using computational approaches to take advantage of this rich resource, network models of the telomere biology have been established, allowing their study.

For example, Schahar et al. used network theory to integrate the list of TLM genes with a large protein-protein interaction database, thus rigorously charting the cellular subnetwork underlying the functions investigated. This method identified pathways connecting TLM gene functions to telomere length maintenance, and, at the same time, expanded the list of TLM genes by identifying nodes in the network that were predicted to participate in the information flow. These mutants either affected essential functions and were not included in the collections, or were not identified in the original screens for technical reasons. The authors experimentally validated some of these predictions, demonstrating that the method developed is remarkably accurate. This analysis, for example, identified the KEOPS complex (identified in parallel by two other groups [89],[90]), and also uncovered a link between the COMPASS histone H3 K4 methylation and the ESCRT vacuolar transport [91].
The telomere length dataset was further used to calibrate the methodology used for charting pathways within networks. A fundamental challenge in network analysis is to chart out the protein pathways that underlie a particular system. Previous approaches to the problem have either employed a local optimization criterion, aiming to infer each pathway independently, or a global criterion, searching for the overall most parsimonious subnetwork. Yosef and co-workers studied the trade-off between the two approaches and developed a new intermediary scheme that provides explicit control over it. This intermediary approach provided the most plausible solutions, which were then validated using molecular genetics approaches. This analysis identified a yet unappreciated link between proteasome activity, DNA repair mechanisms and telomere length maintenance [92].

\section{SECONDARY SCREENS OF $t / m$ MUTANTS}

Secondary screens were also carried out on the $t / m$ mutant collection. In one of these, TLC1 RNA levels were measured in all $t / m$ mutants, and 24 of them were found to affect telomere length via their effect on TLC1 levels [93]. These results identify the mechanism of action of some TIm proteins, and suggest that the level of telomerase RNA may be limiting in telomere length maintenance. The list of mutants included four subunits of Paf1C (Polymerase IIassociated factor complex). While Paf1C had been implicated in the transcription of both polyadenylated and nonpolyadenylated RNAs, it had not been associated previously with the noncoding telomerase RNA. Telomere length in Paf1C mutant strains can be compensated by TLC1 overexpression, suggesting that telomerase RNA is a critical direct or indirect Paf1C target [93].

A second screen explored the effect of starvation on telomere length [94]. Starved cells, or those exposed to the TORC1 inhibitor rapamycin, respond by dramatically shortening their telomeres. Assuming that any signal that affects telomere length must proceed via TLM-controlled pathways, Ungar and co-workers screened the $t / m$ mutants for those that do not respond to the starvation signals. They found that most t/m mutants responded normally to starvation signals; $y k u 70$ and $y k u 80$ mutants, however, fail to respond to rapamycin, indicating that the Ku heterodimer plays a central role in the starvation response. The authors dissected the pathway involved in signal transduction, and found that the TORC1 complex controls the localization of the Gln3 and Gat1 transcription factors. When cells are starved, these factors enter the nucleus and reduce the levels of Ku protein, thus affecting telomere length. This finding is particularly interesting in light of studies suggesting that calorie restriction may lengthen lifespan, whereas telomere attrition leads to cellular senescence [94]. This apparent paradox needs further attention, and will no doubt be the subject of future research.

In another study, that followed the response of yeast telomeres to environmental stimuli, it was found that exposure to ethanol elongates telomeres, whereas caffeine and high temperature reduce telomere length [34]. Again, 
the authors systematically tested $t / m$ mutants looking for those that did not respond or were over-responders to the external signal. They found that different environmental cues seem to act via different pathways; remarkably, ethanol and caffeine required both the activity of Rif1, the Rap1 binding telomeric protein. Rif1 thus is essential for the transmission of both elongating and shortening signals to the telomeres. Interestingly, rif2 strains, as well as mutants of the MRX/Tel1 pathway (analogous to the mammalian MRN/ATM pathway) exhibited a stronger-thanexpected response to ethanol, which causes telomere elongation, indicating that these proteins have a role in preventing length-independent elongation of telomeres. This result is particularly interesting in light of the fact that the MRX/Tel1 pathway is important for telomere elongation, and is believed to play a pivotal role in choosing the shortest telomeres for elongation, thus maintaining the telomere length homeostasis [72]. The work of Romano and co-workers also identified other genes involved in the response to external stimuli: for example, the Nonsense Mediated Decay (NMD) pathway, which regulates the halflife of many RNA molecules in the cell, is important for the response to ethanol. The authors found that this is due to regulation of STN1 mRNA by the NMD; indeed, it is enough to overexpress Stn 1 and Ten 1 in wild type cells to prevent elongation by ethanol (the phenotype observed in $n m d$ mutants), demonstrating that the CST plays a positive role in the response. The vacuolar transport pathway and the chaperone Hsp104 were also found to play important roles in the presence of ethanol. In contrast, caffeine was shown to affect telomere length by controlling the activity of the ATM and ATR-like kinases, Tel1 and Mec1. Surprisingly, all t/m mutants responded to high temperature, suggesting that the response to high temperature is due to an intrinsic inactivation of the telomere machinery itself, rather than a defect in the transmission of a signal [34].

Finally, Jin-Qiu Zhou and colleagues explored the $t / m$ collection looking for mutants that affect the survival pathways in the absence of telomerase activity [95]. Previous work has shown that in the absence of either telomerase's catalytic subunit, its Est co-factors or its template RNA, cells senesce due to constant telomere shortening. From a population of senescing cells, rare survivors arise by recombination-based mechanisms, also known as ALT (Alternative Lengthening of Telomeres)[96]. Survivors are usually of two types: Type I survivors amplify internal subtelomeric repeats, but have telomeric repeats of normal length, whereas Type II have long telomeric repeats. Whereas Type I survivors are more common, they grow slowly, and in liquid cultures are usually overgrown by Type II cells $[96,97]$. Hu and co-workers carried their secondary screen of $t / m$ mutants by knocking out the TLC1 gene, encoding telomerase RNA, in $280 \mathrm{t} / \mathrm{m}$ mutants. They then monitored the patterns of senescence and survival. New functional roles were found for 10 genes that affect the emerging ratio of Type I versus Type II survivors and 22 genes that are required for Type II survivor generation. For example, the Pif1 helicase and the INO80 chromatin remodeling complex reduced the frequency of Type I survi- vors, whereas the KEOPS complex (see below) was shown to be required for Type II recombination [95].

\section{ADDITIONAL GENOME-WIDE SCREENS FOR TELOMERE- RELATED FUNCTIONS}

1) Functions important upon telomere uncapping:

Binding of the $\mathrm{Cdc} 13$ to telomeric ssDNA repeats is essential for telomere protection. Upon transfer of cells carrying the temperature-sensitive $c d c 13-1$ allele to the restrictive temperature, for example, telomeres become "uncapped" and extensive resection of telomeres leads to senescence, cell cycle arrest and cell death. The Lydall lab conducted a systematic screen for mutants that affect growth of a cdc13-1 allele. By crossing a cdc13-1 mutant with the whole non-essential deletion collection, they identified 369 gene deletions that affected growth of cdc13-1 mutants at several temperatures. The mutants could be divided in eight phenotypic categories. The results included many of the checkpoint-affecting genes expected, but also genes in a variety of unexpected categories, such as RNA metabolism and phosphate and iron homeostasis. In addition, the screen identified a number of genes of previously unknown function renamed RTC (restriction of telomere capping) or MTC (maintenance of telomere capping) [89, 98]. The KEOPS (kinase, endopeptidase and other proteins of small size) complex is a good example of a group of proteins with a central role in telomere biology identified in genomewide screens. Mutations in KEOPS members affect telomere length and capping, and were also found in the screen for mutants that affect the kinetics of survivor appearance $[89,95]$. This complex is composed of proteins, some of which are conserved in the three domains of life, and some of which can be found only in fungi: Kae1, a putative endopeptidase with an unknown role, is absolutely conserved in Archea, Bacteria and Eukarya; Bud32, is a serine/threonine kinase with a wide distribution in the tree of life; Pcc1, the yeast homolog of the two human cancertestis antigens that are specifically expressed in different tumors but also in normal testes and ovaries [90], is also widely distributed; Gon7 (also referred to as Pcc2) is a small protein with no known functional domains, found only in fungi; and Cgi121, whose human homolog binds the human Bud32, also known as the p53-related protein kinase [99]. Mutations in KEOPS components partially suppress the temperature-sensitivity of $c d c 13-1$, caused by telomere uncapping. Interestingly, further biochemical work identified the main role of KEOPS as the N6threonylcarbamoylation ( $t(6) A$ ) of tRNA, an essential modification required for translational fidelity by the ribosome [100].

This capping mutant screen was extended, by systematically looking for suppressors or enhancers of the $y k u 70 \Delta$ mutation, and comparing them to the results obtained for cdc13-1. The authors then developed a sophisticated analysis, named QFA (Quantitative Fitness Analysis), which allowed them to dissect the genetic interactions of both capping complexes, CST and $\mathrm{Ku}$. The response to telomere uncapping was shown to be genetically complex, with 
many genes involved in a variety of processes affecting the outcome. Many genes had differential effects: for example, inactivating the Nonsense Mediated Decay (NMD) pathway, which affects half-life of mRNAs in the cells, led to suppression of $c d c 13-1$ but enhanced the phenotype of $y k u 70 \Delta$. The authors showed that this effect is Stn1 dependent, again stressing the pivotal role of the CST in regulating telomere biology [101].

\section{2) Genes important for telomere three-dimensional con- figuration:}

An additional genome-wide screen looked for mutants affecting the telomere three-dimensional configuration. In mammalian cells telomeric DNA forms a loop that allows the ssDNA end to invade telomeric dsDNA forming a Holliday Junction, in a structure that protects the SsDNA end and is called a T-loop [2]. Due to the small size of yeast telomeres, it has been impossible to visualize T-loops in yeast, as has been done in mammals. Instead, functional assays have been used. For example, a construct carrying a TATA-less galactose-inducible UAS (upstream activating sequence) downstream of the URA3 gene is able to transcribe the URA3 gene only at telomeres, where it could fold back on itself, but not at other locations in the genome [3]. The Luke group took advantage of this fact to carry out a genome-wide screen for mutants affecting telomere foldback, looking for those that were unable to express the URA3 construct and could thus grow on medium containing galactose and 5-FOA (which is lethal when URA3 is expressed). This screen identified 112 genes that disrupt looping when mutated [3]. Among various biological processes uncovered, lysine deacetylation was found to be essential for the fold-back through Rif2-dependent recruitment of the Rpd3L complex to telomeres. Absence of Rpd3 function generates increased susceptibility to nucleolytic degradation and the initiation of premature senescence, suggesting a protective role for Rpd3 deacetylation activity [3]. Thus, this work identifies a major mechanism of end protection, together with the way it is recruited to telomeres.

\section{3) Genes affecting the Tel1 (ATM) pathway:}

A screen for enhancers of the MMS sensitivity of tel1 $\triangle \mathrm{mu}$ tants uncovered a small number (13) of genes. These included Yku70, members of the 9-1-1 pathway, the CCR4NOT deadenylase complex, nuclear pore components and several histone deacetylases. Most of these mutants caused the MMS sensitivity due to their effects on telomeres [102]. Interestingly, this report also suggests that shortened telomeres confer sensitivity to DNA damaging agents, such as methyl methanesulfonate (MMS).

\section{REFERENCES}

1. Dewar JM, Lydall D (2012). Similarities and differences between "uncapped" telomeres and DNA double-strand breaks. Chromosoma 121(2): 117-30.

\section{4) Genes affecting senescence:}

The $\mathrm{t} / \mathrm{m}$ collection was screened by $\mathrm{Hu}$ and co-workers, looking for mutants affecting survivor appearance in the absence of telomerase activity [95](see above). A genomewide screen [87] examined, in a systematic fashion, the kinetics of senescence, by crossing the est1 $\Delta$ mutation (lacking an essential telomerase recruitment factor) to the whole nonessential mutant collection. As expected, the vast majority of gene deletions showed no strong effects on the entry into/exit from senescence. However, 200 gene deletions (among them the well-characterized rad52 $\Delta$ mutant) accelerated entry into senescence, and such cells often could not recover growth. A smaller number of strains (among them rif1 $\Delta$ ) accelerated both entry into senescence and subsequent recovery [87]. Interestingly, the mutants that accelerated senescence tended to also have negative genetic interactions with $y k u 70 \Delta$, but were neutral when combined with cdc13-1, as determined in the genome-wide screen described above [101].

Although the Systems Biology revolution is only at its infancy, we can summarize at this stage that the genomewide studies have vastly extended our view of telomere biology. The number of cellular processes affecting various aspects of telomere integrity, replication, length regulation and structure is remarkable. Most of the genes uncovered in these screens are evolutionarily conserved, and likely to act similarly in other organisms, including humans. A better understanding of the mechanisms regulating telomere biology will have significant medical implications, especially in the fields of aging and cancer.

\section{ACKNOWLEDGMENTS}

Work in the Kupiec lab is supported by the Israel Ministry of Science and Technology, the Israel Cancer Research Fund and the Israel Cancer Foundation.

\section{CONFLICT OF INTEREST}

The authors declare no conflict of interest.

\section{COPYRIGHT}

(C) 2014 Harari and Kupiec. This is an open-access article released under the terms of the Creative Commons Attribution (CC BY) license, which allows the unrestricted use, distribution, and reproduction in any medium, provided the original author and source are acknowledged.

Please cite this article as: Yaniv Harari and Martin Kupiec (2014). Genome-wide studies of telomere biology in budding yeast. Microbial Cell 1(3): 70-80. doi: 10.15698/mic2014.01.132

2. Griffith JD, Comeau L, Rosenfield S, Stansel RM, Bianchi A, Moss H, de Lange $T$ (1999). Mammalian telomeres end in a large duplex loop. Cell 97(4): 503-14. 
3. Poschke H, Dees M, Chang M, Amberkar S, Kaderali L, Rothstein R, Luke B (2012). Rif2 promotes a telomere fold-back structure through Rpd3L recruitment in budding yeast. PLoS Genet 8(9): e1002960.

4. Olovnikov AM (1971). [Principle of marginotomy in template synthesis of polynucleotides]. Doklady Akademii nauk SSSR 201(6): 1496-9.

5. Watson JD (1972). Origin of concatemeric T7 DNA. Nature: New biology 239(94): 197-201.

6. Harley CB, Futcher AB, Greider CW (1990). Telomeres shorten during ageing of human fibroblasts. Nature 345(6274): 458-60.

7. Hayflick L (1979). The cell biology of aging. The Journal of investigative dermatology 73(1): 8-14.

8. Lundblad V, Szostak JW (1989). A mutant with a defect in telomere elongation leads to senescence in yeast. Cell 57(4): 633-43.

9. Greider CW, Blackburn EH (1987). The telomere terminal transferase of Tetrahymena is a ribonucleoprotein enzyme with two kinds of primer specificity. Cell 51(6): 887-98.

10. de Lange $T$ (2009). How telomeres solve the end-protection problem. Science 326(5955): 948-52.

11. Bodnar AG, Ouellette M, Frolkis M, Holt SE, Chiu CP, Morin GB, Harley CB, Shay JW, Lichtsteiner S, Wright WE (1998). Extension of life-span by introduction of telomerase into normal human cells. Science 279(5349): 349-52.

12. DeMasters BK, Markham N, Lillehei KO, Shroyer KR (1997). Differential telomerase expression in human primary intracranial tumors. Am J Clin Pathol 107(5): 548-54.

13. Conomos D, Pickett HA, Reddel RR (2013). Alternative lengthening of telomeres: remodeling the telomere architecture. Front Oncol 3(27).

14. Hahn WC, Counter CM, Lundberg AS, Beijersbergen RL, Brooks MW, Weinberg RA (1999). Creation of human tumour cells with defined genetic elements. Nature 400(6743): 464-8.

15. Gramatges MM, Bertuch AA (2013). Short telomeres: from dyskeratosis congenita to sporadic aplastic anemia and malignancy. Translational research : the journal of laboratory and clinical medicine.

16. Armanios M (2012). Telomerase and idiopathic pulmonary fibrosis. Mutation research 730(1-2): 52-8.

17. Calado RT, Young NS (2009). Telomere diseases. The New England journal of medicine 361(24): 2353-65.

18. Lin J, Smith DL, Blackburn EH (2004). Mutant telomere sequences lead to impaired chromosome separation and a unique checkpoint response. Mol Biol Cell 15(4): 1623-34.

19. Shampay J, Szostak JW, Blackburn EH (1984). DNA sequences of telomeres maintained in yeast. Nature 310(5973): 154-7.

20. McEachern MJ, Blackburn EH (1994). A conserved sequence motif within the exceptionally diverse telomeric sequences of budding yeasts. Proc Natl Acad Sci U S A 91(8): 3453-7.

21. Forstemann K, Lingner J (2001). Molecular basis for telomere repeat divergence in budding yeast. Molecular and cellular biology 21(21): 7277-86.

22. McEachern MJ, Blackburn EH (1995). Runaway telomere elongation caused by telomerase RNA gene mutations. Nature 376(6539): 403-9.

23. Marcand S, Wotton D, Gilson E, Shore D (1997). Rap1p and telomere length regulation in yeast. Ciba Foundation symposium 211(76-93); discussion -103.
24. Krauskopf A, Blackburn EH (1998). Rap1 protein regulates telomere turnover in yeast. Proc Natl Acad Sci U S A 95(21): 12486-91.

25. Krauskopf A, Blackburn EH (1996). Control of telomere growth by interactions of RAP1 with the most distal telomeric repeats. Nature 383(6598): 354-7.

26. Pardo B, Marcand S (2005). Rap1 prevents telomere fusions by nonhomologous end joining. Embo J 24(17): 3117-27.

27. Negrini S, Ribaud V, Bianchi A, Shore D (2007). DNA breaks are masked by multiple Rap1 binding in yeast: implications for telomere capping and telomerase regulation. Genes \& development 21(3): 292302.

28. Laroche T, Martin SG, Gotta M, Gorham HC, Pryde FE, Louis EJ, Gasser SM (1998). Mutation of yeast Ku genes disrupts the subnuclear organization of telomeres. Current biology : CB 8(11): 653-6.

29. Tornow J, Zeng X, Gao W, Santangelo GM (1993). GCR1, a transcriptional activator in Saccharomyces cerevisiae, complexes with RAP1 and can function without its DNA binding domain. Embo J 12(6): 2431-7.

30. Zhao Y, McIntosh KB, Rudra D, Schawalder S, Shore D, Warner JR (2006). Fine-structure analysis of ribosomal protein gene transcription. Molecular and cellular biology 26(13): 4853-62.

31. Hardy CF, Sussel L, Shore D (1992). A RAP1-interacting protein involved in transcriptional silencing and telomere length regulation. Genes \& development 6(5): 801-14.

32. Wotton D, Shore D (1997). A novel Rap1p-interacting factor, Rif2p, cooperates with Rif1p to regulate telomere length in Saccharomyces cerevisiae. Genes \& development 11(6): 748-60.

33. Shi T, Bunker RD, Mattarocci S, Ribeyre C, Faty M, Gut H, Scrima A, Rass U, Rubin SM, Shore D, Thoma NH (2013). Rif1 and Rif2 shape telomere function and architecture through multivalent Rap1 interactions. Cell 153(6): 1340-53.

34. Romano GH, Harari Y, Yehuda T, Podhorzer A, Rubinstein L, Shamir R, Gottlieb A, Silberberg Y, Pe'er D, Ruppin E, Sharan R, Kupiec M (2013). Environmental stresses disrupt telomere length homeostasis. PLoS Genet 9(9): e1003721.

35. Pastwa E, Blasiak J (2003). Non-homologous DNA end joining. Acta biochimica Polonica 50(4): 891-908.

36. Rathmell WK, Chu G (1994). Involvement of the Ku autoantigen in the cellular response to DNA double-strand breaks. Proc Natl Acad Sci U S A 91(16): 7623-7.

37. Taccioli GE, Gottlieb TM, Blunt T, Priestley A, Demengeot J, Mizuta R, Lehmann AR, Alt FW, Jackson SP, Jeggo PA (1994). Ku80: product of the XRCC5 gene and its role in DNA repair and $V(D) J$ recombination. Science 265(5177): 1442-5.

38. Gravel S, Larrivee M, Labrecque P, Wellinger RJ (1998). Yeast Ku as a regulator of chromosomal DNA end structure. Science 280(5364): 741-4.

39. Roy R, Meier B, McAinsh AD, Feldmann HM, Jackson SP (2004). Separation-of-function mutants of yeast Ku80 reveal a Yku80p-Sir4p interaction involved in telomeric silencing. J Biol Chem 279(1): 86-94.

40. Marvin ME, Becker MM, Noel P, Hardy S, Bertuch AA, Louis EJ (2009). The association of $y K u$ with subtelomeric core $X$ sequences prevents recombination involving telomeric sequences. Genetics 183(2): 453-67, 1SI-13SI.

41. Mimitou EP, Symington LS (2010). Ku prevents Exo1 and Sgs1dependent resection of DNA ends in the absence of a functional MRX complex or Sae2. Embo J 29(19): 3358-69. 
42. Bonetti D, Clerici M, Anbalagan S, Martina M, Lucchini G, Longhese MP (2010). Shelterin-like proteins and $\mathrm{Yku}$ inhibit nucleolytic processing of Saccharomyces cerevisiae telomeres. PLoS Genet 6(5): e1000966.

43. Bonetti D, Clerici M, Manfrini N, Lucchini G, Longhese MP (2010). The MRX complex plays multiple functions in resection of $\mathrm{Yku}$ - and Rif2-protected DNA ends. PloS one 5(11): e14142.

44. Ribes-Zamora A, Mihalek I, Lichtarge O, Bertuch AA (2007). Distinct faces of the $\mathrm{Ku}$ heterodimer mediate DNA repair and telomeric functions. Nat Struct Mol Biol 14(4): 301-7.

45. Lopez CR, Ribes-Zamora A, Indiviglio SM, Williams CL, Haricharan S, Bertuch AA (2011). Ku must load directly onto the chromosome end in order to mediate its telomeric functions. PLoS Genet 7(8): e1002233.

46. Churikov D, Corda Y, Luciano P, Geli V (2013). Cdc13 at a crossroads of telomerase action. Front Oncol 3(39).

47. Sun J, Yang Y, Wan K, Mao N, Yu TY, Lin YC, DeZwaan DC, Freeman $B C$, Lin JJ, Lue NF, Lei M (2011). Structural bases of dimerization of yeast telomere protein $\mathrm{Cdc13}$ and its interaction with the catalytic subunit of DNA polymerase alpha. Cell research 21(2): 258-74.

48. Grandin N, Charbonneau M (2013). RPA provides checkpointindependent cell cycle arrest and prevents recombination at uncapped telomeres of Saccharomyces cerevisiae. DNA Repair (Amst) 12(3): 212-26

49. Luciano P, Coulon S, Faure V, Corda Y, Bos J, Brill SJ, Gilson E, Simon MN, Geli V (2012). RPA facilitates telomerase activity at chromosome ends in budding and fission yeasts. Embo J 31(8): 203446.

50. Schramke V, Luciano P, Brevet V, Guillot S, Corda Y, Longhese MP, Gilson E, Geli V (2004). RPA regulates telomerase action by providing Est1p access to chromosome ends. Nature genetics 36(1): 46-54

51. Grandin N, Damon C, Charbonneau M (2001). Ten1 functions in telomere end protection and length regulation in association with Stn1 and Cdc13. Embo J 20(5): 1173-83.

52. Grandin N, Reed SI, Charbonneau M (1997). Stn1, a new Saccharomyces cerevisiae protein, is implicated in telomere size regulation in association with Cdc13. Genes \& development 11(4): 512-27.

53. Petreaca RC, Chiu HC, Eckelhoefer HA, Chuang C, Xu L, Nugent Cl (2006). Chromosome end protection plasticity revealed by Stn $1 p$ and Ten1p bypass of Cdc13p. Nature cell biology 8(7): 748-55.

54. Sun J, Yu EY, Yang Y, Confer LA, Sun SH, Wan K, Lue NF, Lei M (2009). Stn1-Ten1 is an Rpa2-Rpa3-like complex at telomeres. Genes \& development 23(24): 2900-14.

55. Rusche LN, Kirchmaier AL, Rine J (2003). The establishment, inheritance, and function of silenced chromatin in Saccharomyces cerevisiae. Annual review of biochemistry 72:481-516.

56. Hughes TR, Evans SK, Weilbaecher RG, Lundblad V (2000). The Est3 protein is a subunit of yeast telomerase. Current biology : CB 10(13): 809-12.

57. Lendvay TS, Morris DK, Sah J, Balasubramanian B, Lundblad V (1996). Senescence mutants of Saccharomyces cerevisiae with a defect in telomere replication identify three additional EST genes. Genetics 144(4): 1399-412.

58. Tuzon CT, Wu Y, Chan A, Zakian VA (2011). The Saccharomyces cerevisiae telomerase subunit Est3 binds telomeres in a cell cycle- and Est1-dependent manner and interacts directly with Est1 in vitro. PLoS Genet 7(5): e1002060.
59. Taggart AK, Teng SC, Zakian VA (2002). Est1p as a cell cycleregulated activator of telomere-bound telomerase. Science 297(5583): 1023-6.

60. Evans SK, Lundblad V (2002). The Est1 subunit of Saccharomyces cerevisiae telomerase makes multiple contributions to telomere length maintenance. Genetics 162(3): 1101-15.

61. DeZwaan DC, Freeman BC (2009). The conserved Est1 protein stimulates telomerase DNA extension activity. Proc Natl Acad Sci U S A 106(41): 17337-42.

62. Aylon $Y$, Kupiec M (2003). The checkpoint protein Rad24 of Saccharomyces cerevisiae is involved in processing double-strand break ends and in recombination partner choice. Molecular and cellular biology 23(18): 6585-96.

63. Garvik B, Carson M, Hartwell L (1995). Single-stranded DNA arising at telomeres in cdc13 mutants may constitute a specific signal for the RAD9 checkpoint. Molecular and cellular biology 15(11): 6128-38.

64. Mieczkowski PA, Mieczkowska JO, Dominska M, Petes TD (2003). Genetic regulation of telomere-telomere fusions in the yeast Saccharomyces cerevisae. Proc Natl Acad Sci U S A 100(19): 10854-9.

65. Marcand S, Pardo B, Gratias A, Cahun S, Callebaut I (2008). Multiple pathways inhibit NHEJ at telomeres. Genes \& development 22(9): 1153-8.

66. Faure V, Coulon S, Hardy J, Geli V (2010). Cdc13 and telomerase bind through different mechanisms at the lagging- and leading-strand telomeres. Molecular cell 38(6): 842-52.

67. Maringele L, Lydall D (2002). EXO1-dependent single-stranded DNA at telomeres activates subsets of DNA damage and spindle checkpoint pathways in budding yeast yku70Delta mutants. Genes \& development 16(15): 1919-33.

68. Vodenicharov MD, Laterreur N, Wellinger RJ (2010). Telomere capping in non-dividing yeast cells requires Yku and Rap1. Embo J 29(17): 3007-19.

69. Teixeira MT, Arneric M, Sperisen P, Lingner J (2004). Telomere length homeostasis is achieved via a switch between telomeraseextendible and -nonextendible states. Cell 117(3): 323-35.

70. Raghuraman MK, Winzeler EA, Collingwood D, Hunt S, Wodicka L, Conway A, Lockhart DJ, Davis RW, Brewer BJ, Fangman WL (2001) Replication dynamics of the yeast genome. Science 294(5540): 115-21.

71. Ferguson BM, Fangman WL (1992). A position effect on the time of replication origin activation in yeast. Cell 68(2): 333-9.

72. Chang M, Arneric M, Lingner J (2007). Telomerase repeat addition processivity is increased at critically short telomeres in a Tel1dependent manner in Saccharomyces cerevisiae. Genes \& development 21(19): 2485-94.

73. Evans SK, Lundblad V (1999). Est1 and Cdc13 as comediators of telomerase access. Science 286(5437): 117-20.

74. Osterhage JL, Talley JM, Friedman KL (2006). Proteasomedependent degradation of Est1p regulates the cell cycle-restricted assembly of telomerase in Saccharomyces cerevisiae. Nat Struct Mol Biol 13(8): 720-8.

75. Gallardo F, Laterreur N, Cusanelli E, Ouenzar F, Querido $E$, Wellinger RJ, Chartrand $P$ (2011). Live cell imaging of telomerase RNA dynamics reveals cell cycle-dependent clustering of telomerase at elongating telomeres. Molecular cell 44(5): 819-27.

76. Clerici M, Mantiero D, Guerini I, Lucchini G, Longhese MP (2008) The Yku70-Yku80 complex contributes to regulate double-strand break processing and checkpoint activation during the cell cycle. EMBO reports 9(8): 810-8. 
77. Castrillo JI, Oliver SG (2011). Yeast systems biology: the challenge of eukaryotic complexity. Methods Mol Biol 759:3-28.

78. Winzeler EA, Shoemaker DD, Astromoff A, Liang $H$, Anderson $K$, Andre B, Bangham R, Benito R, Boeke JD, Bussey H, Chu AM, Connelly C, Davis K, Dietrich F, Dow SW, El Bakkoury M, Foury F, Friend SH, Gentalen E, Giaever G, Hegemann JH, Jones T, Laub $M$, Liao $H$, Liebundguth N, Lockhart DJ, Lucau-Danila A, Lussier M, M'Rabet N, Menard $P$, et al. (1999). Functional characterization of the $S$. cerevisiae genome by gene deletion and parallel analysis. Science 285(5429): 901-6.

79. Breslow DK, Cameron DM, Collins SR, Schuldiner M, StewartOrnstein J, Newman HW, Braun S, Madhani HD, Krogan NJ, Weissman JS (2008). A comprehensive strategy enabling high-resolution functional analysis of the yeast genome. Nature methods 5(8): 711-8.

80. Ben-Aroya S, Coombes C, Kwok T, O'Donnell KA, Boeke JD, Hieter P (2008). Toward a comprehensive temperature-sensitive mutant repository of the essential genes of Saccharomyces cerevisiae. Molecular cell 30(2): 248-58.

81. Costanzo M, Baryshnikova A, Bellay J, Kim Y, Spear ED, Sevier CS, Ding H, Koh JL, Toufighi K, Mostafavi S, Prinz J, St Onge RP, VanderSluis B, Makhnevych T, Vizeacoumar FJ, Alizadeh S, Bahr S, Brost RL, Chen Y, Cokol M, Deshpande R, Li Z, Lin ZY, Liang W, Marback M, Paw J, San Luis BJ, Shuteriqi E, Tong AH, van Dyk N, et al. (2010). The genetic landscape of a cell. Science 327(5964): 425-31.

82. Askree SH, Yehuda T, Smolikov S, Gurevich R, Hawk J, Coker C, Krauskopf A, Kupiec M, McEachern MJ (2004). A genome-wide screen for Saccharomyces cerevisiae deletion mutants that affect telomere length. Proc Natl Acad Sci U S A 101(23): 8658-63.

83. Gatbonton $T$, Imbesi $M$, Nelson M, Akey JM, Ruderfer DM, Kruglyak L, Simon JA, Bedalov A (2006). Telomere length as a quantitative trait: genome-wide survey and genetic mapping of telomere length-control genes in yeast. PLoS Genet 2(3): e35.

84. Ungar L, Yosef N, Sela Y, Sharan R, Ruppin E, Kupiec M (2009). A genome-wide screen for essential yeast genes that affect telomere length maintenance. Nucleic Acids Res.

85. Ben-Shitrit T, Yosef N, Shemesh K, Sharan R, Ruppin E, Kupiec M (2012). Systematic identification of gene annotation errors in the widely used yeast mutation collections. Nature methods 9(4): 373-8.

86. Ballew BJ, Lundblad V (2013). Multiple genetic pathways regulate replicative senescence in telomerase-deficient yeast. Aging cell 12(4): 719-27.

87. Chang HY, Lawless C, Addinall SG, Oexle S, Taschuk M, Wipat A, Wilkinson DJ, Lydall D (2011). Genome-wide analysis to identify pathways affecting telomere-initiated senescence in budding yeast. G3 (Bethesda) 1(3): 197-208.

88. Rog O, Smolikov S, Krauskopf A, Kupiec M (2005). The yeast VPS genes affect telomere length regulation. Current genetics $47(1)$ : 18-28.

89. Downey M, Houlsworth R, Maringele L, Rollie A, Brehme M, Galicia S, Guillard S, Partington M, Zubko MK, Krogan NJ, Emili A, Greenblatt JF, Harrington L, Lydall D, Durocher D (2006). A genome-wide screen identifies the evolutionarily conserved KEOPS complex as a telomere regulator. Cell 124(6): 1155-68.
90. Kisseleva-Romanova E, Lopreiato R, Baudin-Baillieu A, Rousselle JC, Ilan L, Hofmann K, Namane A, Mann C, Libri D (2006). Yeast homolog of a cancer-testis antigen defines a new transcription complex. Embo J 25(15): 3576-85.

91. Shachar R, Ungar L, Kupiec M, Ruppin E, Sharan R (2008). A systems-level approach to mapping the telomere length maintenance gene circuitry. Mol Syst Biol 4:172.

92. Yosef N, Ungar L, Zalckvar E, Kimchi A, Kupiec M, Ruppin E, Sharan $R$ (2009). Toward accurate reconstruction of functional protein networks. Mol Syst Biol 5:248.

93. Mozdy AD, Podell ER, Cech TR (2008). Multiple yeast genes, including Paf1 complex genes, affect telomere length via telomerase RNA abundance. Molecular and cellular biology 28(12): 4152-61.

94. Ungar L, Harari $Y$, Toren A, Kupiec M (2011). Tor complex 1 controls telomere length by affecting the level of Ku. Current biology : CB 21(24): 2115-20.

95. Hu Y, Tang HB, Liu NN, Tong XJ, Dang W, Duan YM, Fu XH, Zhang Y, Peng J, Meng FL, Zhou JQ (2013). Telomerase-null survivor screening identifies novel telomere recombination regulators. PLoS Genet 9(1): e1003208.

96. Teng SC, Zakian VA (1999). Telomere-telomere recombination is an efficient bypass pathway for telomere maintenance in Saccharomyces cerevisiae. Molecular and cellular biology 19(12): 8083-93.

97. Grandin N, Charbonneau M (2007). Control of the yeast telomeric senescence survival pathways of recombination by the Mec1 and Mec3 DNA damage sensors and RPA. Nucleic acids research 35(3): 822-38.

98. Addinall SG, Downey M, Yu M, Zubko MK, Dewar J, Leake A Hallinan J, Shaw O, James K, Wilkinson DJ, Wipat A, Durocher D, Lydall $D$ (2008). A genomewide suppressor and enhancer analysis of cdc13-1 reveals varied cellular processes influencing telomere capping in Saccharomyces cerevisiae. Genetics 180(4): 2251-66.

99. Miyoshi A, Kito K, Aramoto T, Abe Y, Kobayashi N, Ueda N (2003). Identification of CGI-121, a novel PRPK (p53-related protein kinase)binding protein. Biochem Biophys Res Commun 303(2): 399-405.

100. Wan LC, Mao DY, Neculai D, Strecker J, Chiovitti D, Kurinov I, Poda G, Thevakumaran N, Yuan F, Szilard RK, Lissina E, Nislow C, Caudy AA, Durocher D, Sicheri F (2013). Reconstitution and characterization of eukaryotic N6-threonylcarbamoylation of tRNA using a minimal enzyme system. Nucleic Acids Res 41(12): 6332-46.

101. Addinall SG, Holstein EM, Lawless C, Yu M, Chapman K, Banks AP, Ngo HP, Maringele L, Taschuk M, Young A, Ciesiolka A, Lister AL, Wipat A, Wilkinson DJ, Lydall D (2011). Quantitative fitness analysis shows that NMD proteins and many other protein complexes suppress or enhance distinct telomere cap defects. PLoS Genet 7(4): e1001362.

102. Piening BD, Huang D, Paulovich AG (2013). Novel connections between DNA replication, telomere homeostasis, and the DNA damage response revealed by a genome-wide screen for TEL1/ATM interactions in Saccharomyces cerevisiae. Genetics 193(4): 1117-33. 